\title{
Mediational effects as a function of Stage 3 mediator presentation'
}

Mediator presentation in Stage 3 was studied by presenting the mediator, $A$, with the stimulus $B$, in Stage 3 of an A-B, $A-C, B-C$ paradigm. Additional Stage 3 conditions involved standard B-C acquisition, presentation of a repaired mediator with $\mathrm{B}$, and presentation of a control word, $X$, with B. In general, the condition involving mediator presentation and the standard condition did not differ significantly from each other, but both were superior to the repaired mediator and control conditions. The relation of the present findings to the role of the mediator in Stage 3 is discussed, with the suggestion that although the mediator produced superior acquisition compared to the repaired and control conditions, the lack of difference of mediator presentation and the standard condition suggests that occurrence of the mediator in Stage 3 may be of limited importance in obtaining mediation effects.

Mediation in the $\mathrm{A}-\mathrm{B}, \mathrm{A}-\mathrm{C}, \mathrm{B}-\mathrm{C}$ paradigm is defined in terms of superior $B-C$ performance of the experimental as opposed to the control $(A-B, D-C, B-C)$ conditions. A recent experiment demonstrated that for high $M$ words, the mediator is readily available at the end of Stage 2 acquisition (Popp \& Voss, 1965). However, it also was found that mediator recall decreased as a function of $\mathrm{B}-\mathrm{C}$ trials although mediation effects in terms of correct responses nevertheless were found. The present experiment therefore was designed to provide information regarding the role of the mediator in Stage 3. Four Stage 3 conditions were employed: (1) standard B-C learning; (2) B-C learning with A presented; (3) B-C learning with A presented, but repaired with a different B-C pair; (4) B-C learning with a word, $\mathrm{X}$, employed to control for the presentation of an additional word per se. If mediator availability is important to mediational effects, then it was anticipated that Condition 2 should facilitate $\mathrm{B}-\mathrm{C}$ acquisition, but Condition 3 should interfere with B-C acquisition. Method

Procedure. A three-stage A-B, A-C, B-C paradigm was employed. Six paired-associates were presented by the anticipation method via Carousel projector at a 2:2sec. rate with a 4-sec. intertrial interval. Between each stage of learning there was a 2-min. digit cancellation task. Four Stage 3 experimental conditions were employed: Condition S-standard B-C learning; Condition A-the mediator, A, was presented with the stimulus, B, in Stage 3; Condition Ar-the mediator, A, was presented with a B stimulus other than the B item with which it had been associated (repaired condition); Condition $\mathrm{X}$ - a control word, $\mathrm{X}$, not previously used, was presented with the stimulus, $B$, in Stage 3 . This condi- tion was included in order to control for presentation of a word with the stimulus, B, in Stage 3. Each list was learned to a $6 / 6$ criterion.

Following Stage 3 acquisition, recall and recognition tasks were given. The $\mathrm{B}$ and $\mathrm{C}$ words were individually presented on $3 \times 5$ cards at a rate of $1 / 10-$ sec. Order of $\mathrm{B}$ and $\mathrm{C}$ presentation was counterbalanced. The Ss were asked to recall the word associated in the first two stages with B or C. Following recall, Ss matched the stimulus-response pairs from Stage 1 and Stage 2. Order of matching with respect to Stage 1 and Stage 2 pairs was counterbalanced.

Materials and Subjects. The words were selected from the Melton-Safier list (Hilgard, 1961). The pairs were identical to those used by Popp and Voss (1965). Instructions were typical paired-associate instructions except that in Conditions A, Ar, and X in Stage 3, Ss were instructed that they would see a word occur with the stimulus in Stage 3 and that they should try to use that word to help them learn the Stage 3 pairs. The $\mathrm{N} /$ condition was 10 .

\section{Results}

An analysis of variance performed upon the $A-B$ and A-C trials to criterion data revealed no significant difference in Stage 1 or Stage 2 acquisition as a function of experimental condition, $F<1.00, \mathrm{df}=3 / 36$ for Stage $1, \mathbf{F}<\mathbf{1 . 0 0 ,} \mathrm{df}=3 / 36$ for Stage 2 .

Table 1 presents Stage 3 mean trials to criterion for the four experimental conditions. An analysis of variance revealed a significant experimental condition source of variation, $F=3.89, \mathrm{df}=3 / 36, p<.05$. Analyses of the data further revealed that Conditions $S$ and A do not differ significantly from each other $(F<1.00)$ nor do Conditions $\mathrm{Ar}$ and $\mathrm{X}(F<1.00)$ differ significantly from each other. However, Condition A differs significantly from Condition $\mathrm{Ar}, \mathrm{F}=8.15, \mathrm{df}=1 / 18$, $\mathrm{p}<.05$, and from Condition $\mathrm{X}, \mathrm{F}=4.43, \mathrm{df}=1 / 18, \mathrm{p}<.05$. Condition $\mathrm{S}$ differs significantly from Condition Ar, $F=6.30, \mathrm{df}=1 / 18, \mathrm{p}<.05$, but does not differ significantly from Condition $X, F=2.89$, $d f=1 / 18$. Thus, with one exception, Conditions $\mathrm{A}$ and $\mathrm{S}$ yielded Stage 3 per-

Table 1. Summary of Stage 3 Performance Measures

\begin{tabular}{lccc}
$\begin{array}{l}\text { Exp. } \\
\text { Cond. }\end{array}$ & $\begin{array}{c}\text { Mean Trial } \\
\text { to Criterion }\end{array}$ & $\begin{array}{c}\text { Mean Trials to } \\
\text { lst Correct R }\end{array}$ & $\begin{array}{c}\text { Mean Prop. } \\
\text { Correct R }\end{array}$ \\
\hline $\mathrm{S}$ & 9.5 & 3.7 & .86 \\
$\mathrm{~A}$ & 8.3 & 4.8 & .91 \\
$\mathrm{Ar}$ & 15.2 & 5.6 & .79 \\
$\mathrm{X}$ & 13.2 & 7.1 & .76 \\
\hline
\end{tabular}


formance significantly superior to Conditions Ar and X.

The second column of Table 1 presents mean trials to the first correct response for each experimental condition. An analysis of variance revealed a significant experimental condition source of variation, $F=4.41$, $\mathrm{df}=3 / 36, \mathrm{p}<.01$. Subsequent analyses revealed that Condition $S$ was superior to Condition $\mathrm{Ar}, F=19.13, \mathrm{df}=1 / 18$, $\mathrm{p}<.01$, and Condition $\mathrm{S}$ was superior to Condition $\mathrm{X}$, $\mathrm{F}=8.65, \mathrm{df}=1 / 18, \mathrm{p}<.01$. No other pair comparisons are significant. These data indicate: (1) presentation of the mediator did not yield more rapid $\mathrm{B}-\mathrm{C}$ acquisition than any other condition; (2) presence of a word with the stimulus yielded poorer performance than standard $\mathrm{B}-\mathrm{C}$ acquisition although Conditions $\mathrm{S}$ and $\mathrm{A}$ do not differ significantly.

The third column of Table 1 presents mean proportion of correct responses, once a correct response has been made. In other words, it is the proportion of correct responses that occurred inclusively between the first correct response and the criterion trial. The mean proportion for each $S$ was submitted to an arcsin transformation and the transformed data were analyzed. Despite the relatively large differences between Conditions $\mathrm{S}$ and $\mathrm{A}$ vs. Conditions $\mathrm{Ar}$ and $\mathrm{X}$, the analysis revealed no significant difference as a function of experimental condition.

Table 2 presents recall frequencies for each experimental condition. "Neither" refers to the frequency of Ss recalling neither B-A nor C-A correctly, "Both" refers to correct recall of both $\mathrm{B}-\mathrm{A}$ and $\mathrm{C}-\mathrm{A}$, and "Either" refers to the correct recall for $\mathrm{B}-\mathrm{A}$ or $\mathrm{C}-\mathrm{A}$. The recall data clearly show the superiority of Condition A in recall. The same finding occurred with the recognition

Table 2. Summary of B-A and C-A Recall

\begin{tabular}{lccc} 
Cond. & $\begin{array}{c}\text { Neither } \\
\text { B-A nor C-A }\end{array}$ & $\begin{array}{c}\text { Recall } \\
\text { Either } \\
\text { B-A or C-A }\end{array}$ & $\begin{array}{c}\text { Both } \\
\text { B-A and C-A }\end{array}$ \\
\hline $\mathrm{S}$ & 35 & 12 & 13 \\
$\mathrm{~A}$ & 7 & 25 & 28 \\
$\mathrm{Ar}$ & 40 & 11 & 9 \\
$\mathrm{X}$ & 44 & 10 & 6 \\
\hline $\mathrm{S}$ & & Recognition & 35 \\
$\mathrm{~A}$ & 5 & 20 & 42 \\
$\mathrm{Ar}$ & 6 & 12 & 22 \\
$\mathrm{X}$ & 12 & 26 & 19 \\
\hline
\end{tabular}

data, although recognition frequency in Conditions $A$ and $\mathrm{S}$ is more similar than correct recall frequency. Discussion

The results of the present experiment indicate: (1) presentation of the mediator in Stage 3 yielded superior performance compared to Conditions $\mathrm{Ar}$ and $\mathrm{X}$; (2) presentation of the mediator in Stage 3 did not yield performance superior to Condition $\mathrm{S}$. The first finding implies that $S$ is using the mediator for acquisition of the $\mathrm{B}-\mathrm{C}$ pairs in Condition $\mathrm{A}$. The major question of the present results, however, is why Conditions $\mathrm{S}$ and A differed so little except in recall.

The following speculation is offered regarding performance similarity in Conditions A and S: (1) Lack of a significant difference in Conditions $S$ and $A$ for various performance measures does not necessarily mean that $\mathrm{B}-\mathrm{C}$ acquisition took place in the same manner under the two conditions. (2) The lack of a significant difference between Condition $A$ and the other three conditions in trials to the first correct response suggests Ss do not chain in a B-A-C manner, for following Stage 2 learning, Condition $A$ should have produced rapid learning. (3) Although the data are not directly related to the issue, they are consonant with the notion that $\mathrm{A}$ acts to integrate B-C as a unit (Popp \& Voss, 1965). (4) The lack of difference in Conditions $S$ and A suggests that mediator availability in Stage 3 may, in fact, have little to do with mediation effects. This notion leads to the question of whether mediation effects may be attributable to earlier stage effects and not Stage 3 mediation (Jenkins, 1963; Kjeldergaard, 1966; Morning \& Voss, 1964).

\section{References}

Hilgard, E. R. Methods and procedures in the study of learning. In S. S. Stevens (Ed.), Handbook of experimental psychology. New York: Wiley, 1951. Pp. 517-567.

Jenkins, J. J. Mediated associations: Paradigms and situations. In C. N. Cofer \& B. S. Musgrwve (Eds.), Verbal behavior and learning. New York: McGraw-Hill, 1963.

Kjeldergaard, P. M. Transfer and mediation in verbal learning. Symposium: University of Kentucky, 1966.

Morning, N., \& Voss, J. F. Mediation of $R_{1}-R_{2}$ in the acquisition of S-R 1 , S-R $R_{2}$ associations. J. exp. Psychol., 1964, 67, 67-71.

Popp, R., \& Voss, J. F. Mediation effects as a function of mediator recall and meaningfuIness. Paper presented at Psychonomic Society, Chicago, Illinois, 1965.

\section{Note}

1. The research reported in this paper was supported by the National Institute of Child Health and Human Development(HD 00957-03). 